\title{
Jahresbericht der Musikabteilung für 2009
}

\author{
Von Ute Becker
}

\section{Neuerwerbungen und Neuzugänge}

Aus dem Wiener Buch- und Kunstantiquariat Wolfgang Mantler konnte das im Jahr 1686 bei Ludwig Baldinger in Basel gedruckte Enchiridion Alterum Responsoria Festivitatum erworben werden.

Ein Musikmanuskript „Die Entschlafenen“ des 1901 in Karlsruhe geborenen Komponisten Hans Erich Apostel gelangte aus dem Antiquariat Kohl in die Württembergische Landesbibliothek. Ebenfalls dort wurden zwei eigenhändige Briefe der Komponisten Max von Pauer (1866-1945) und Karl Marx (1897-1985) erworben, die als Musikpädagogen an der Stuttgarter Musikhochschule wirkten.

Zwei Handschriften von August Otto Halm verkaufte der renommierte Bachforscher und Professor der Universität Tübingen Ulrich Siegele der Landesbibliothek. Zwei weitere, Halm betreffende Handschriften aus dem Nachlass seines Vaters Willi Siegele, überließ er der WLB als Geschenk.

Das Werk des 1931 in Schwäbisch Gmünd geborenen Komponisten Arthur Dangel umfasst neben zahlreichen Stücken für Orchester und Chor auch eine große Anzahl von kammermusikalischen Kompositionen, zahlreiche Lieder sowie Werke für Orgel und Klavier. Im vergangenen Jahr wurde die Übertragung seines autographen Nachlasses an die Württembergische Landesbibliothek testamentarisch festgelegt.

Besonders zu erwähnen ist überdies der mit Hans Georg Bertram vereinbarte Vorlass seiner Kompositionen. Bertram wurde 1936 in Gießen geboren, studierte in Stuttgart und prägte das Musikleben der Region entscheidend mit - durch seine knapp 20 Jahre währende Lehre an der Hochschule für Kirchenmusik in Esslingen und durch seine Tätigkeit als Organist an der dortigen Stadtkirche.

Auch die Gesangbuchsammlung wurde im vergangenen Jahr beständig erweitert.

Ferner bereichert seit Ende des Jahres die bei Ashgate verlegte Reihe Music in Medieval Europe den Bestand der Musiksammlung.

\section{Projekte}

Der musikalische Teil des Hofbibliotheksbestandes war auch im Jahr 2009 eines der großen Themen für die Musikabteilung. Bereits vor einigen Jahren wurde im Rahmen des Landesrestaurierungsprogramms damit begonnen, Stimmenmaterial aus dem HB-XVII-Bestand zu restaurieren. Im Jahr 2009 lag der Schwerpunkt auf der Restaurierung von Opernpartituren. Diese soll im Laufe des Jahres 2010 abgeschlossen werden.

Im Juli 2009 kam es zu einer weiteren umfangreichen Ablieferung von Aufführungsmaterialien des Staatstheaters.

Im Rahmen des von der Deutschen Forschungsgemeinschaft geförderten Projekts „Musik und Bühne am Stuttgarter Hoftheater im 19. Jahrhundert" wurde unter der Leitung von Prof. Dr. Silke Leopold und Prof. Dr. Dörte Schmidt eine weitere 
Datenbank angelegt, die Theaterzettel, Textbücher und Musikalien des Hoftheaters recherchierbar macht. Die etwa 2300 Datensätze können nun auf Erstaufführungen des Hoftheaters der Zeit 1807-1899 im Bereich Oper, Schauspiel und Ballett durchsucht werden.

An der Entstehung dieser Datenbank waren Dr. Andreas Münzmay, Dr. Antje Tumat und Jessica Riemer M.A. beteiligt. Frau Tumat befasst sich auch künftig mit den Beständen der Musiksammlung und wird im Rahmen des Editionsprojekts OPERA Spektrum des europäischen Musiktheaters in Einzeleditionen Peter Joseph von Lindpaintners Faust herausgeben. Träger dieses Projekts ist die Akademie der Wissenschaften und der Literatur, Mainz, die Projektleitung obliegt Prof. Dr. Thomas Betzwieser.

Herr Dr. Jörg Martin führte nicht nur die Erschließung des Nachlasses von Helmut Bornefeld zu Ende, sondern war darüber hinaus auch mit der Erschließung des Nachlasses betraut, der Materialien von August Otto Halm enthält bzw. Dokumente von Willi Siegele, die Halm betreffen.

Der umfangreiche Nachlass des Musikpädagogen, Komponisten und Publizisten Hugo Herrmann wurde von Dr. Michael Strobel katalogisiert. Die Erschließungsdaten können über die Datenbank „Musik- und Musikerhandschriften“ abgerufen werden.

\section{Ausstellungen}

Am 28. Oktober wurde in der Bibliothèque Nationale et Universitaire (BNU) der Stadt Straßburg, der Partnerbibliothek der Württembergischen Landesbibliothek, eine Ausstellung zu Friedrich Hölderlin eröffnet. Die BNU zeigte auch Stücke aus dem Bestand der WLB, darunter 11 bedeutendende Werkhandschriften Hölderlins und zwei Stücke aus der Musiksammlung: eine bei Schott erschienene Studien- und Dirigierpartitur der siebten Symphonie von Hans Werner Henze und die „Kreisleriana Fantasien für das Pianoforte“, Robert Schumanns Opus 16.

Im Rahmen der Ausstellung „Egmont: Goethe - Schiller - Beethoven“ waren in der WLB ab dem 2. November "Lieder und Gesänge mit Begleitung des Pianoforte componirt von Ludwig van Beethoven" zu sehen, und zwar in einer Ausgabe von Breitkopf \& Härtel, die vermutlich aus dem Jahr 1846 stammt. Ebenfalls ausgestellt war eine von Breitkopf \& Härtel verantwortete Partitur von Beethovens Opus 84, der „Musik zu Egmont“.

\section{Personalia}

Am 19. Oktober trat die Musikwissenschaftlerin Frau Dr. Ute Abele ihren zweijährigen Vorbereitungsdienst an. Während des ersten Jahres ihres Referendariats wird sie in der WLB praktische Erfahrungen sammeln und die verschiedenen Abteilungen und Arbeitsbereiche des Hauses kennen lernen. Das zweite Jahr an der Bayerischen Bibliotheksschule in München wird der theoretischen Ausbildung gewidmet sein.

Zuerst veröffentlicht in: „Jahrbuch der Musik in Baden-Württemberg“, Bd. 17 (2010) Berichte aus den Musikabteilungen der Landesbibliotheken 